\title{
The Intra- and Intercellular Movement of Melon necrotic spot virus (MNSV) Depends on an Active Secretory Pathway
}

\author{
Ainhoa Genovés, Jose Antonio Navarro, and Vicente Pallás \\ Instituto de Biología Molecular y Celular de Plantas, Universidad Politécnica de Valencia-CSIC, Avenida de los Naranjos s/n, \\ 46022 Valencia, Spain
}

Submitted 15 September 2009. Accepted 5 November 2009.

Plant viruses hijack endogenous host transport machinery to aid their intracellular spread. Here, we study the localization of the $\mathrm{p7B}$, the membrane-associated viral movement protein (MP) of the Melon necrotic spot virus (MNSV), and also the potential involvement of the secretory pathway on the p7B targeting and intra- and intercellular virus movements. p7B fused to fluorescent proteins was located throughout the endoplasmic reticulum (ER) at motile Golgi apparatus (GA) stacks that actively tracked the actin microfilaments, and at the plasmodesmata (PD). Hence, the secretory pathway inhibitor, Brefeldin A (BFA), and the overexpression of the GTPase-defective mutant of Sar1p, Sar1[H74L], fully retained the p7B within the ER, revealing that the protein is delivered to $P D$ in a BFA-sensitive and COPII-dependent manner. Disruption of the actin cytoskeleton with latrunculin $B$ led to the accumulation of p7B in the ER, which strongly suggests that p7B is also targeted to the cell periphery in an actin-dependent manner. Remarkably, the local spread of the viral infection was significantly restricted either with the presence of BFA or under the overexpression of $\operatorname{Sar} 1[\mathrm{H} 74 \mathrm{~L}]$, thus revealing the involvement of an active secretory pathway in the intracellular movement of MNSV. Overall, these findings support a novel route for the intracellular transport of a plant virus led by the GA.

To move from cell to cell, plant viruses overcome the cell wall barrier by traversing it through specialized pores called plasmodesmata (PD). To accomplish this task, they use different virus-encoded factors termed movement proteins (MP) (Waigmann et al. 2004; Lucas 2006). A great variety of strategies for intracellular viral transport linked to MP diversity have been described, all of which depend heavily on endogenous host transport machinery (Boevink et al. 1998; Nelson and Citrovsky 2005). For example, Tobacco mosaic virus (TMV) cell-to-cell movement depends on a $30-\mathrm{kDa}$ protein, which shares structural similarities with a large number of plant virus MP (the $30 \mathrm{~K}$ superfamily) (Melcher 2000). During intracellular movement, the TMV MP associates with endoplasmic reticulum (ER)-derived membranous bodies that are induced by an active 126-kDa replicase when viral RNA is ER-

Corresponding author: Vicente Pallás; Telephone: +34 963877877, Fax: +34 963877859, E-mail: vpallas@ibmcp.upv.es

* The $\boldsymbol{e}$-Xtra logo stands for "electronic extra" and indicates that three supplementary figures and a video presentation of p7B motility are published online and that Figures 1, 2, 4, 5, and 6 appear in color online. anchored by means of its $5^{\prime}$ methylguanosine cap (Hirashima and Watanabe 2003; Kawakami et al. 2004; Christensen et al. 2009). Then, virus replicase and MP most likely control the actin- or myosin-dependent movement of the viral replication complex (VRC) toward and through the PD channel, where both proteins function together in altering PD conductivity (Heinlein et al. 1998; Lui et al. 2005; Guenoune-Gelbart et al. 2008; Harries et al. 2009). However, the driven force controlling the VRC transport to the cell periphery is still a not-wellunderstood mechanism that requires the interaction of MP with either an intact cytoskeleton or just individual components of both microfilaments and microtubules (Gillespie et al. 2002; Ashby et al. 2006; Wright et al. 2007; Brandner et al. 2008; Sambade et al. 2008; Harries et al. 2009; Hofmann et al. 2009). On the other hand, the MP of the tubule-forming Grapevine fanleaf virus (GFLV) can reach PD using the plant secretory pathway by traveling along either microtubules under normal conditions or actin microfilaments when microtubules are lacking (Laporte et al. 2003). In contrast, the PD targeting of the tubule-forming MP of the Cowpea mosaic virus (CPMV) is not affected by the disruption of either the secretory pathway or the cytoskeleton (Pouwels et al. 2002). In transgenic Arabidopsis plants, the Potato leafroll virus (PLRV) MP17 is targeted to PD in an actin- and secretory pathway-dependent manner (Vogel et al. 2007), as drug-inhibitory treatments have established.

Beyond MP belonging to the $30 \mathrm{~K}$ superfamily, in two groups of positive-strand RNA viruses (potex-like and hordeilike viruses), the movement function is provided by the proteins encoded by the so-called triple gene block (TGB), including an RNA-binding protein with helicase activity (TGBp1) and two small membrane-associated proteins (TGBp2 and TGBp3). TGBp2 and TGBp3 move from the ER to the cellular periphery by means of ER-derived vesicles which also travel along the actin or myosin microfilaments. This targeting was shown to be dependent on interactions between the TGB2 and TGB3 proteins (Morozov and Solovyev 2003; Ju et al. 2005, 2007; Samuels et al. 2007; Verchot-Lubicz et al. 2007; Schepetilnikov et al. 2008; Jackson et al. 2009; Lim et al. 2009). Moreover, it is also known that the Pomovirus membrane-associated TGB can be recycled by the endocytic pathway (Haupt et al. 2005).

Finally, other viral factors different from MP such as the Tomato spotted wilt virus (TSWV) glycoproteins ( $\mathrm{Gn}$ and $\mathrm{Gc}$ ) have been also observed at the ER-export sites and the Golgi complex upon coexpression (Ribeiro et al. 2008). The transmembrane domain (TMD) of Gn is sufficient to exit from the ER toward the Golgi apparatus (GA), and inhibition of ER- 
Golgi transport modifies the localization pattern of these viral glycoproteins (Ribeiro et al. 2009). Nevertheless, whether this inhibition would block the viral movement remains unknown.

In this work, we use one of the simplest multicomponent transport systems identified to date, such as the Carmovirus genus, which is extremely reduced in the case of Melon necrotic spot virus (MNSV). The MNSV genome codes for five functionally characterized proteins (Riviere and Rochon 1990; Genoves et al. 2006) and two small proteins are directly involved in the virus movement, p7A and p7B (Genoves et al. 2006; Gosalvez-Bernal et al. 2008). p7B has a single-TMD domain, roughly spanning from the $S_{14}$ to the $L_{32}$ residue, which allows protein insertion into the ER-derived microsomal membranes obtained in vitro (Navarro et al. 2006; Martínez-Gil et al. 2007).

Here, we study the subcellular location of the p7B of MNSV in Nicotiana benthamiana plants by transiently expressing either the green fluorescent protein (GFP)-p7B or red fluorescent protein (RFP)-p7B constructs in the presence of different known organelle markers. We show how the $\mathrm{p} 7 \mathrm{~B}$ was localized at the ER, Golgi stacks, and PD. Treatments with either specific drugs or protein organelle inhibitors revealed the actin-dependent
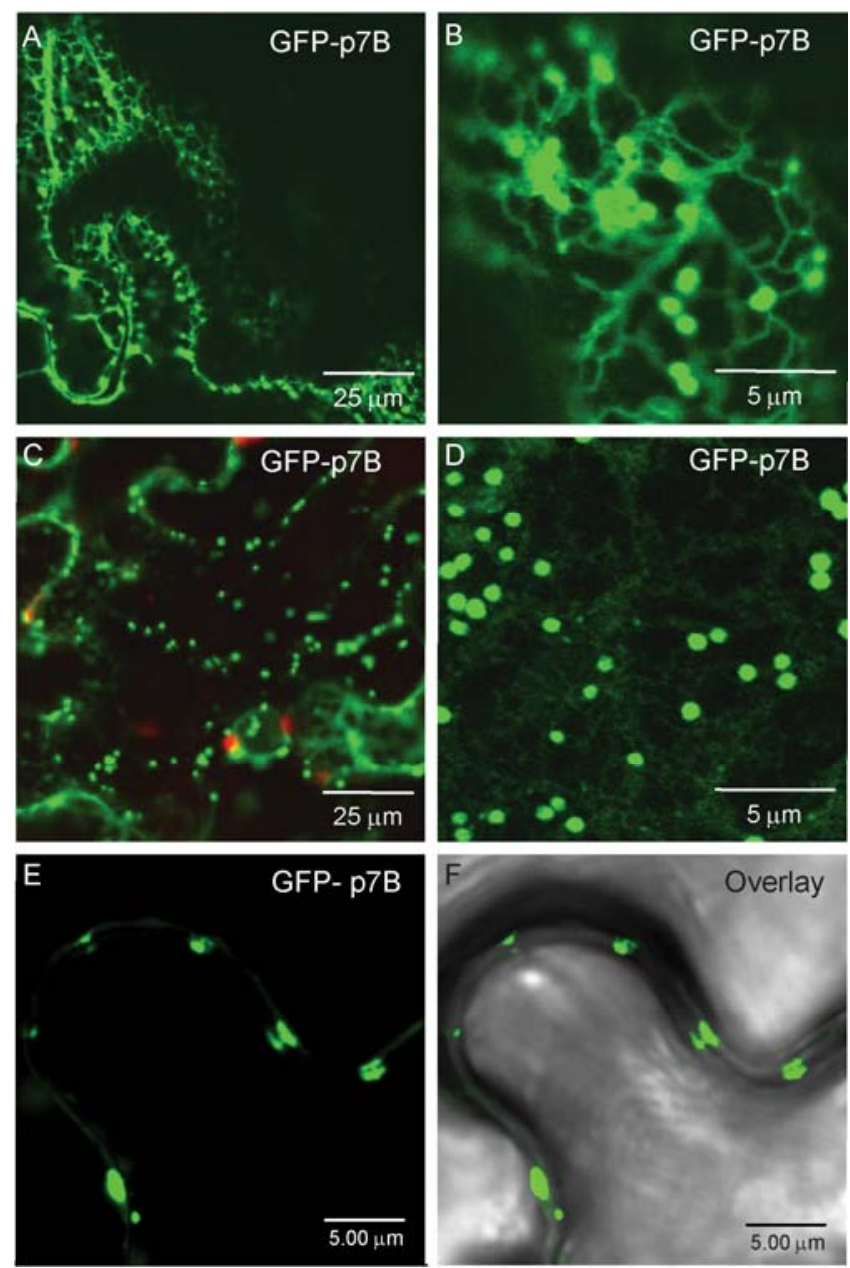

Fig. 1. Studies on the subcellular localization of p7B from Melon necrotic spot virus fused to green fluorescent protein (GFP) in Nicotiana benthamiana leaves through transient expression. A through D, Confocal laser composite images of the epidermal cells expressing GFP-p7B taken at $\mathbf{A}$ and $\mathbf{B}, 24$ to 36 and $\mathbf{C}$ through $\mathbf{F}, 36$ to $72 \mathrm{~h}$ postinfiltration and showing a fluorescent polygonal network pattern (A and B) which turns into network-associated punctate bodies (C and D); red fluorescence in $\mathrm{C}$ correspond with chloroplast autofluorescence. $\mathbf{E}$ and $\mathbf{F}$, GFP-p7B pattern is on the boundaries between adjacent epidermal cells like immobile structures; $\mathrm{F}$ is a bright-field image.
ER-Golgi trafficking of p7B to the cell periphery. Finally, chemical or protein inhibitors were used to study the role of the secretory pathway in MNSV cell-to-cell movement. Collectively, our results demonstrate that a functional Golgi-mediated secretory pathway is essential for the intra- and intercellular movement of a plant virus.

\section{RESULTS}

The p7B localizes at the ER, GA, and PD.

To visualize the intracellular distribution of the $\mathrm{p} 7 \mathrm{~B}$ protein, we used $N$. benthamiana leaves expressing GFP-p7B after agroinfiltration. At 24 to $36 \mathrm{~h}$ postinfiltration (hpi), the fluorescence protein labeled an intracellular network (Fig. 1A and B), as well as numerous small and mobile punctate structures distributed within the cell cytoplasm (Fig. 1B; Supplementary Movie). Interestingly at 36 to $72 \mathrm{hpi}$, the GFP-p7B protein was essentially located at these punctate structures (Fig. 1C and D). At this time, the protein was also located in the punctate areas at the cell periphery which were occasionally detected in opposite locations (Fig. E and F).

In order to dissect the subcellular structures involved in this localization pattern, several organelle-specific markers were used. The coexpression of the monomeric (m)RFP-p7B with the lumenal ER marker, GFP-KDEL, revealed a co-localization of the $\mathrm{p} 7 \mathrm{~B}$ within or alongside (as for punctate bodies) the $\mathrm{ER}$, as limited by the resolution of this system (Fig. 2A through $\mathrm{C}$ ). To determine whether the cytoplasmic punctuate structures were associated to some of the major membranebounded organelles, we expressed either the GFP-p7B or the mRFP-p7B with the TMD of the rat $\alpha-2,6$-sialyltransferase (STtmd), as the Golgi trans face protein, or with the cis face marker Gman-GFP (mannosidase Golgi's resident). Interestingly, p7B co-localized with both the STtmd (Fig. 2D through F) and the Gman (Fig. 2G through I) proteins. In contrast, no p7B co-localization was observed when we used as a marker either the type I peroxisomal targeting signal (Fig. 2J through L) or the fluorescent ATPase of cellular mitochondria (Fig. 2M through $\mathrm{O}$ ). Overall, these results indicate the localization of the p7B cytoplasm motile bodies at the Golgi stacks. According to the fact that the actin-cytoskeleton supports the motility of the GA (Avisar et al. 2008), coexpression with an actintargeted recombinant protein (RFP-Talin) showed that the GFP-p7B bodies were located on the actin filaments (Fig. 2P through R). Moreover, their movement was halted (Supplementary Fig. 1), most likely as a consequence of the expression of the acting marker in agreement with the previous report (Holweg 2007). Therefore, these GFP-p7B bodies were most probably not moving only by cytoplasmic streaming but also by active involvement of microfilaments (either by microfilament polymerization or myosin-mediated movement). Finally, because Golgi fluorescence may appear as a double structure across cell boundaries due to the effects of the cell wall on the reflection and the scattering of light (Liu et al. 2008), a long time-lapse sequence was performed. Unlike this organelle, the p7B punctate structures at the cell periphery were immobile, suggesting that they were indeed associated with PD (data not shown). Given that the TMV MP and the Arabidopsis thaliana class 1 reversibly glycosylated polypeptide fused to GFP (AtRGP2-GFP) are both known to associate with the PD, we corroborated that the $\mathrm{p} 7 \mathrm{~B}$ peripheral pattern corresponded with PD because GFP-p7B co-localized with the TMV MP fused to the mRFP open reading frame $(\mathrm{ORF})\left(\mathrm{MP}_{\mathrm{TMV}^{-}}\right.$ mRFP) (Fig. 2S through U) and RFP-p7B with AtRGP2-GFP (Fig. 2V through $\mathrm{X}$ ).

To provide further evidence that the GFP-p7B bodies associate with Golgi stacks, the average velocities of both these 
labeled particles were quantified. The resulting rates were $0.919( \pm 0.416) \mu \mathrm{m} \mathrm{s} \mathrm{s}^{-1}$ and $0.928( \pm 0.430) \mu \mathrm{m} \mathrm{s}^{-1}(n=40$ particles), respectively. These values are comparable with the rates already described for Golgi velocity in tobacco leaf epidermal cells and BY-2 cells: 0.76 and $3 \mu \mathrm{m} \mathrm{s}^{-1}$, respectively (Boevink and Oparka 2005; Yang et al. 2005). Therefore, these results, in total, suggest that the viral $\mathrm{MP}, \mathrm{p} 7 \mathrm{~B}$, is inserted into the ER, moves to the GA, and then associates with the PD.
The GFP-p7B co-fractionates with a Golgi marker after microsomal membrane fractionation.

To further corroborate the Golgi association of p7B, a biochemical approach was performed by subcellular fractionation of the protein extracts derived from the $N$. benthamiana plants expressing GFP-p7B. The immunoblot analysis revealed that p7B was present in the crude (P30) microsomal fraction following centrifugation at $30,000 \times g$ (data not shown) but not in
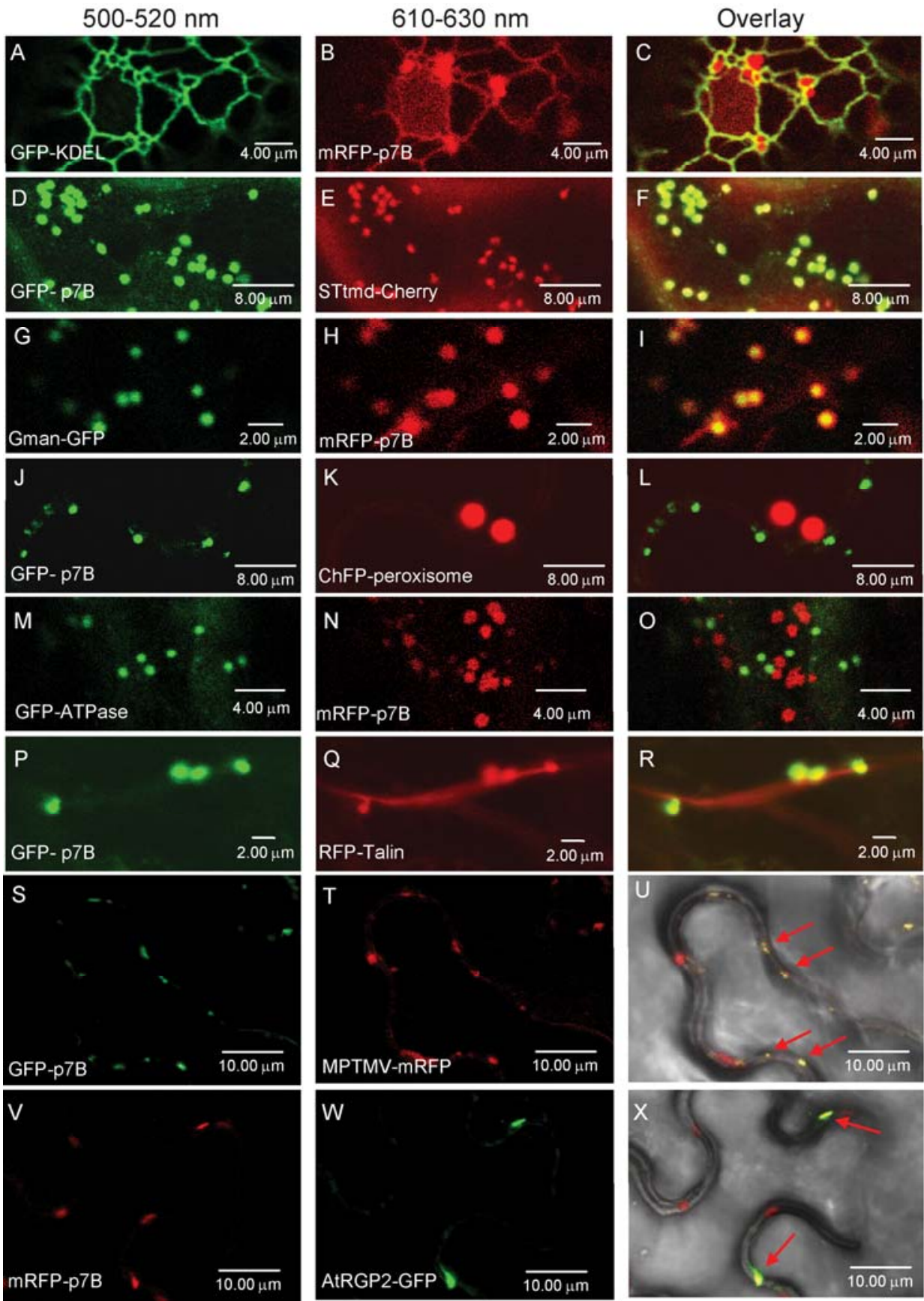

Fig. 2. Confocal laser scans of the epidermal cells coexpressing green fluorescent protein (GFP)-p7B or monomeric red fluorescent protein (mRFP)-p7B together with fluorescent-tagged markers of different subcellular compartments. Overlay images of both red and green channels are displayed in the image column on the right. A through C, mRFP-p7B punctate bodies showing a clear association with the endoplasmic reticulum (ER) labeled by GFP-KDEL. D through F, Co-localization of the GFP-p7B punctate bodies with the Golgi apparatus stacks stained by the STtmd-Cherry. G through I, Co-localization of the mRFP-p7B punctate bodies with the trans Golgi apparatus marker Gman-GFP. $\mathbf{J}$ through $\mathbf{L}$, No co-localization of the GFP-p7B punctate bodies with peroxisomes (red signal). $\mathbf{M}$ through $\mathbf{O}$, No co-localization of the mRFP-p7B with mitochondrial ATPase (GFP-ATPase). P through R, GFP-p7B punctate bodies showing a clear association with the actin microfilaments stained with the RFP-Talin. S and T, Co-expression of the GFP-p7B and the Tobacco mosaic virus (TMV) movement protein (MP) fused to the mRFP open reading frame (MP TMV-mRFP) as a plasmodesmal marker. $\mathbf{V}$ through $\mathbf{X}$, Cells coexpressing mRFP-p7B and the Arabidopsis thaliana reversibly glycosylated polypeptide fused to GFP (AtRGP2-GFP) for plasmodesmata (PD) labeling. Overlay images of the red, green, and white light channels showing the co-localization of the viral protein and the PD markers on the boundaries between the adjacent epidermal cells are displayed to the right of the image ( $\mathrm{U}$ and $\mathrm{X})$; red arrows indicate co-labeled PD. 
the supernatant (S30). Because the P30 fraction contains membrane-derived microsomes, we assumed that $\mathrm{p} 7 \mathrm{~B}$ is, indeed, a membrane-associated protein. The P30 fraction was loaded into the top 20 to $60 \%$ of the linear sucrose density gradient and centrifuged at $100,000 \times g$ for $16 \mathrm{~h}$. Then, the gradient was fractionated and analyzed by anti-GFP immunoblotting (Fig. 3). Moreover, extracts from the leaves separately expressing GFP, STtmd-yellow fluorescent protein (YFP), and GFPKDEL were used as controls. In agreement with the former results, the GFP-p7B and the Golgi-specific marker STtmd-YFP was observed together in the membranous fraction (P30) and the same gradient fractions, 13 to 15 (data not shown) (Fig. 3), whereas the free GFP was present in the soluble fraction (S30) (data not shown). In contrast, luminal GFP-KDEL was mainly recovered from the loading fractions (1 to 4$)$. Thus, the GFPp7B was located at the membrane-derived microsomes fraction of the cell, confirming that it is, indeed, a membrane-associated protein which most likely forms part of the GA structures.

\section{Disruption of either the actin cytoskeleton or the ER-to-Golgi secretion route inhibits GFP-p7B forward trafficking.}

To investigate the potential involvement of the plant secretory pathway in the trafficking of the viral MP p7B, chemical or protein inhibitors were used. Brefeldin A (BFA), a known inhibitor of the ARF-GEF (ADP-ribosylation guanine nucleotide exchange factors), arrests vesicle trafficking along the secretory pathway and leads to the redistribution of the Golgi membrane protein to the ER (Ritzenthaler et al. 2002), whereas the overexpression of the GTPase-defective mutant of Sar1p (Sar1[H74L]) specifically inhibits the COPII-mediated ER-to-Golgi trafficking (Takeuchi et al. 2000). To monitor the effect of treatments, the STtmd-YFP-expressing tissue was simultaneously assayed as a control. As a result, the tissue treated with BFA or that overex-

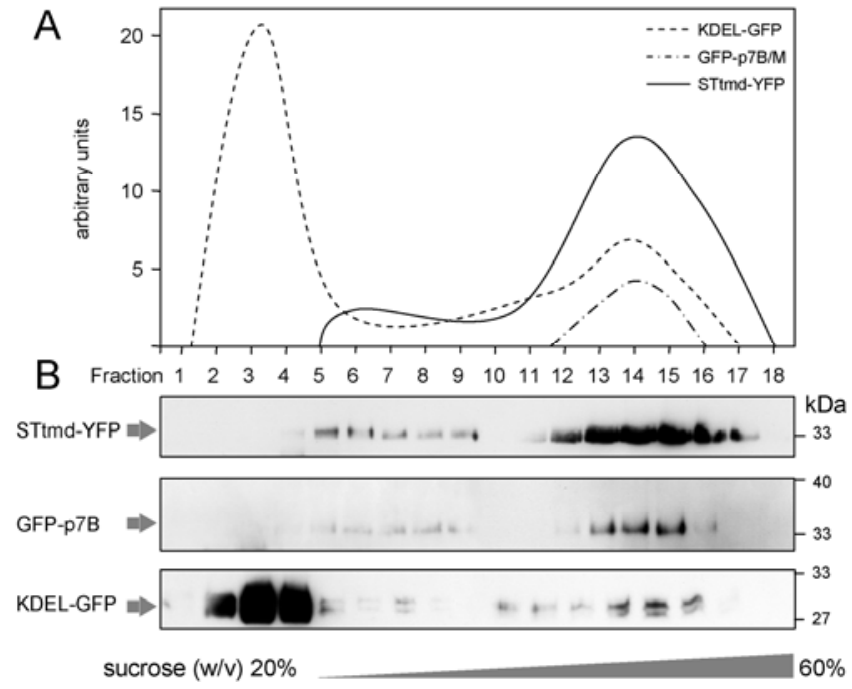

Fig. 3. Biochemical assay for the subcellular fractionation of the Nicotiana benthamiana tissue transiently expressing green fluorescent protein (GFP)p7B, GFP-KDEL, or STtmd-yellow fluorescent protein (YFP). The microsomal (P30) fraction was loaded into the top 20 to $60 \%$ linear sucrose gradients containing lysis buffer with $\mathrm{mM} \mathrm{MgCl}_{2}$, and 18 fractions were taken for the immunoblot analysis using a mouse polyclonal antibody against GFP/YFP. A, Quantification in arbitrary units of the signals derived from the immunoblot assay of each sucrose gradient fraction showing a co-migration of both GFP-tagged p7Bs, one with a luminal endoplasmic reticulum (ER) marker (GFP-KDEL) and the other with a Golgi apparatus marker (STtmd-YFP). B, Immunoblot assays of the sucrose gradient fraction from the $N$. benthamiana tissues expressing STtmd-YFP (Golgi apparatus marker), GFP-p7B, and GFP-KDEL (ER marker). The fractions are numbered from the top to the bottom (1 to 18) of the gradient. pressing Sar1[H74L] resulted in the redistribution of fluorescence into large ER-Golgi hybrid bodies for both proteins, the GFP-p7B (Fig. 4A through C) and the control STtmd-YFP (Fig. 4D through F). Overall, these data demonstrate that the transport of GFP-p7B to the Golgi depends on active ER-Golgi trafficking. Furthermore, GFP-p7B mostly lost its PD location pattern with the presence of BFA (Fig. 4G and I) or after the overexpression of the Sar1[H74L] mutant (Fig. 4J and L). This observation supports the involvement of an active ER-Golgi route in GFP-p7B trafficking to reach PD. Under these conditions, the TMV MP was still observed at these organelles (Fig. 4H, I, K, and $\mathrm{L}$ ), because the reabsorption of the Golgi bodies into the ER had no effect on the TMV MP targeting in PD, as expected (Wright et al. 2007).

On the other hand, because a functional actin-myosin system is involved in both the ER and the Golgi motility in plants (Lichtscheidl and Baluska 2000), we performed an assay in the presence of the actin inhibitor, latrunculin B (LatB) $(25 \mu \mathrm{M}$ in dimethyl sulfoxide [DMSO]), which is known to depolymerize
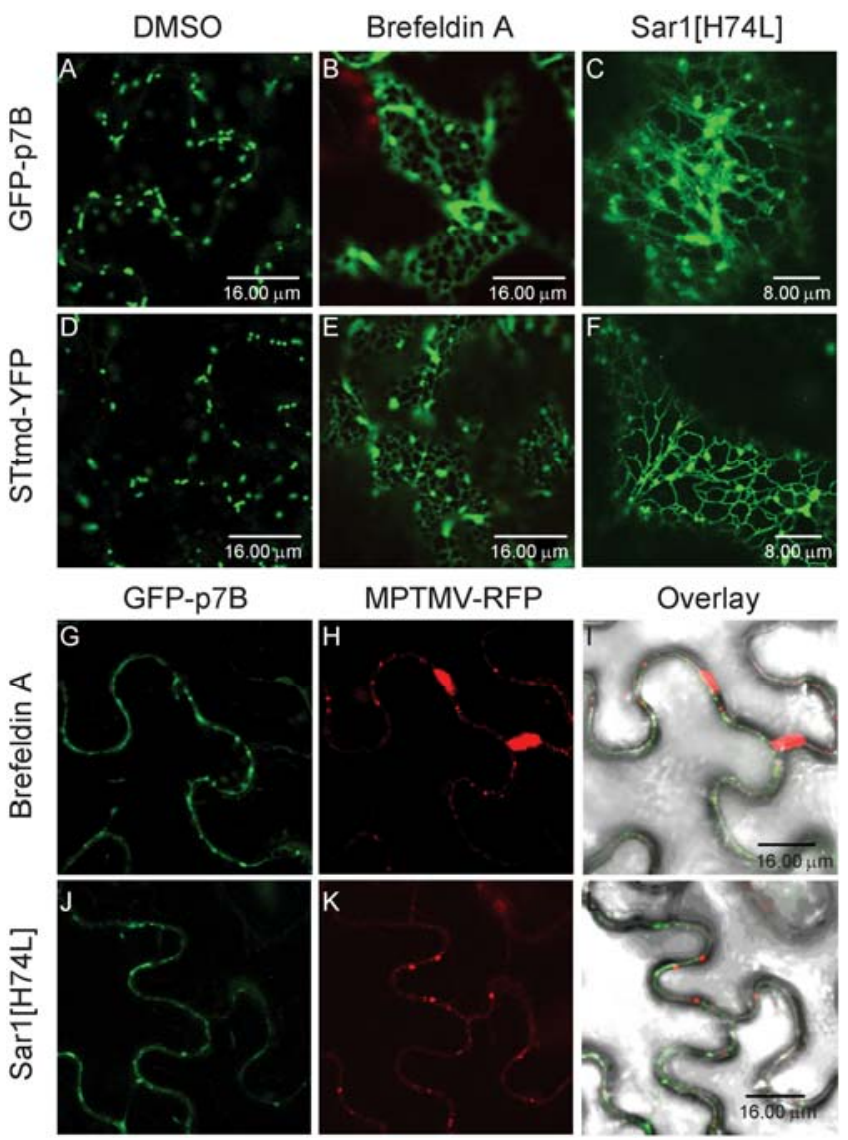

Fig. 4. Effect of Brefeldin A and Sar1[H74L] on fluorescence distribution in the epidermal cells of the Nicotiana benthamiana leaves that transiently express green fluorescent protein (GFP)-p7B, the rat $\alpha-2,6$ sialyltransferase fused to the yellow fluorescent protein (YFP) (STtmdYFP), or the Tobacco mosaic virus (TMV) movement protein (MP) fused to the red fluorescent protein (RFP) (MPTMV-RFP). Drug treatment led to the almost complete redistribution of the fluorescence derived from GFPp7B from A, the Golgi apparatus (GA) stack into B, the endoplasmic reticulum, and had the same effect on the localization of STtmd-YFP (compare the dimethyl sulfoxide [DMSO] control in D with panel E). A similar distribution was observed after the overexpression of the Sar1[H74L] mutant to either C, GFP-p7B or F, STtmd-YFP. Although GFP-p7B has been localized in plasmodesmata, it remains retained in the endoplasmic reticulum in the presence of $\mathbf{G}$, the drug or $\mathbf{J}$, Sar1[H74L], while $\mathbf{H}$ and $\mathbf{K}$, MPTMV-RFP is in the plasmodesmata. $\mathbf{I}$ and $\mathbf{L}$, Overlay of the red, green, and white light channels showing no co-localization under these conditions. 

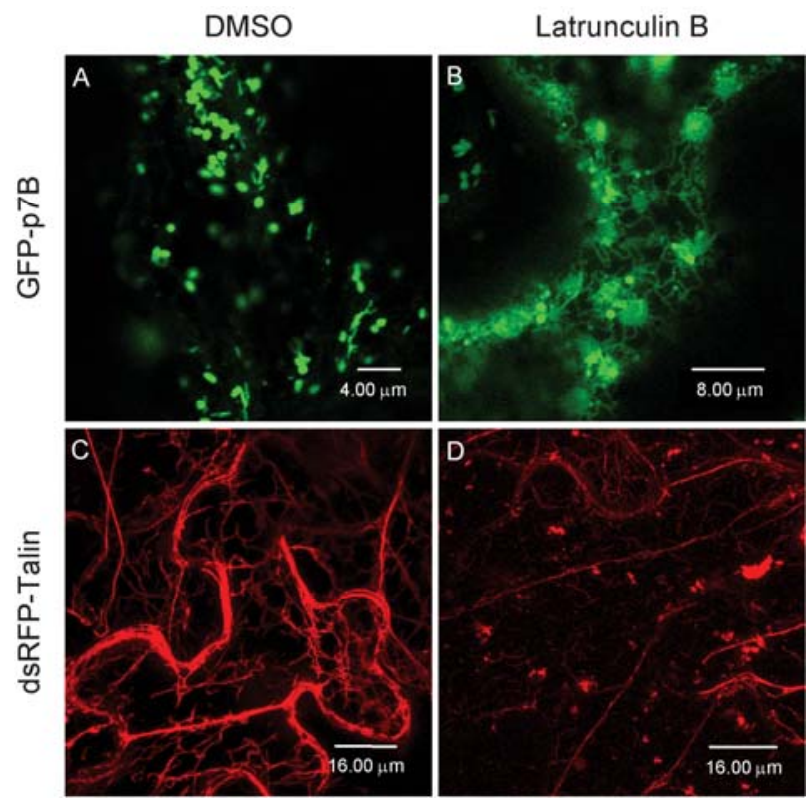

Fig. 5. Effect of Latrunculin B on the fluorescence distribution in the epidermal cells of the Nicotiana benthamiana leaves that transiently express either green fluorescent protein (GFP)-p7B or the actin-binding domain of the mouse talin fused to the dsRFP (dsRFP-Talin). B, Drug treatment led to the almost complete redistribution of the fluorescence derived from GFP-p7B from the Golgi apparatus (GA) stack to the endoplasmic reticulum (ER). D, Effect on the dsRFP-Talin subcellular pattern after drug treatment. The subcellular distribution in the presence of dimethyl sulfoxide (DMSO) (control conditions) of both the A, GFP-p7B and C, dsRFPTalin proteins. filamentous actin (F-actin) in eukaryotic cells. At $5 \mathrm{~h}$ posttreatment, either GFP-p7B or RFP-Talin showed their typical distribution pattern in the mock-treated DMSO leaves (Fig. 5A and $\mathrm{C}$, respectively). Treatment of the $N$. benthamiana leaves with LatB resulted in an aberrant ER-Golgi network after the GFP-p7B expression (Fig. 5B). The drug also exerted the expected effects on the distribution of the RFP-Talin fluorescence (Fig. 5D). Therefore, these results suggest a correlation between the GFP-p7B distribution pattern and an intact actin cytoskeleton.

\section{Disruption of ER-Golgi traffic reduces MNSV infection.}

Because an active secretory pathway was necessary for the intracellular trafficking of MNSV p7B, we reasoned that the disruption of the ER-Golgi traffic would affect virus infection. To test this hypothesis, $N$. benthamiana plants were first infiltrated with the MNSV(Al/264)- $\Delta \mathrm{cp}$-GFP clone, then subsequently treated with either BFA (Fig. 6) or the mutant Sar1[H74L] (Fig. 7). A significant difference in the distribution of the infection foci size was observed for BFA treatment (Fig. 6). In the presence of the drug, the percentage of small infection foci (1 to 5 cells) was higher than in the control leaves with DMSO (67.3 versus $41.0 \%$, respectively). In addition, the average size of the infection foci in BFA-treated leaves $(2.47 \pm 1.10)$ was significantly smaller than in the control (3.16 \pm 0.99$)$, as deduced by the Student's $t$ test for the statistical significance of the difference between the means. In contrast, the number of foci containing more than 6 cells lowered in relation to the control (31.3 versus $56.8 \%$, respectively) and also decreased in size in the presence of BFA $(9.11 \pm 3.5$ versus $12.2 \pm 4.99$ cells). The accumulation level of viral ge-

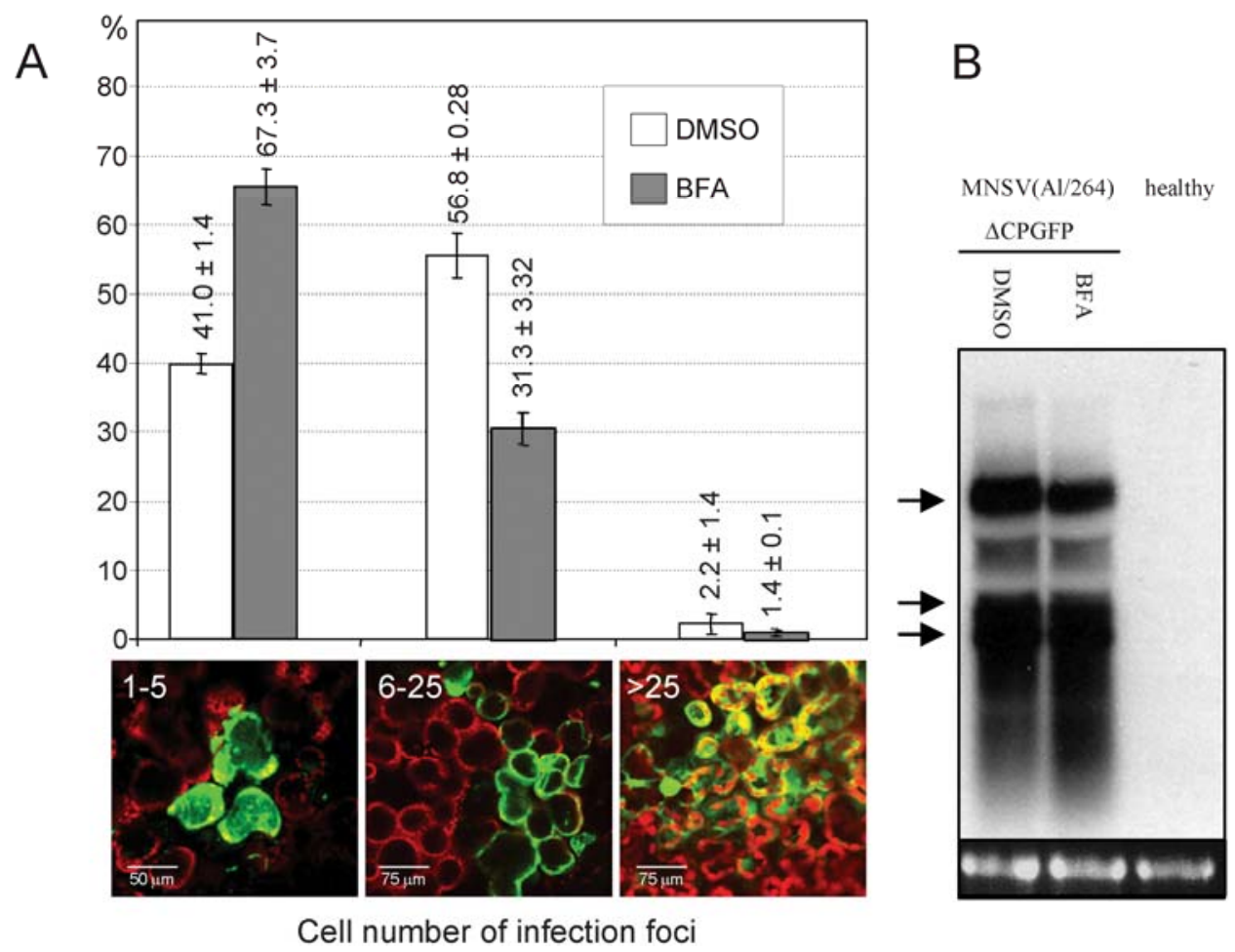

Fig. 6. Effect of Brefeldin A (BFA) on Melon necrotic spot virus (MNSV) cell-to-cell movement. A, Bar diagram representing the percentage of MNSV

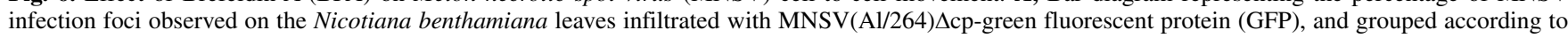
size. Dimethyl sulfoxide (DMSO) treatment was performed as a control (gray bars). The means and standard deviations from two different experiments are indicated above each bar. The size of the infection foci (measured as the number of fluorescent cells), together with the representative confocal microscope image, are displayed under the corresponding bars. B, Detection by Northern-blot analysis of MNSV RNAs in the N. benthamiana leaves infiltrated with MNSV(Al/264) $\Delta$ cp-GFP and treated with DMSO (left) or BFA (center). The total RNA extracts obtained from mock-inoculated plants were used as healthy controls (right). MNSV genomic and subgenomic RNAs positions are indicated on the left. Relative sample loading is inferred from ethidium bromide staining of the plant ribosomal RNA (bottom panel). 
nomic and subgenomic RNAs was similar in both cases for tissue collected immediately after visual analysis, suggesting that replication or accumulation is not significantly affected by the presence of the drug (Fig. 6B), whereas BFA treatment had a negative impact on MNSV cell-to-cell movement. To discard an indirect effect of BFA treatment on plant cellular functions affecting MNSV cell-to-cell movement, an additional control was performed by mechanical inoculation of a quimeric $\mathrm{Al}$ falfa mosaic virus (AMV) RNA 3 expressing GFP on transgenic N. tabacum p12 plants containing an active AMV replicase (Sanchez-Navarro et al. 2001). The AMV MP has been structurally related with the $30 \mathrm{~K}$ superfamily and it can be functionally replaced by other related MP, including the TMV MP (Sanchez-Navarro et al. 2006). Leaves were treated with either BFA or DMSO and the AMV infection progress was visualized as before. On this occasion, there was no significant difference in the area of the GFP-fluorescence foci between control and BFA-treated leaves (data not shown), indicating that BFA did not inhibit the cell-to-cell movement of AMV as has been reported for Tomato mosaic virus (ToMV) MP targeting to PD and viral cell-to-cell movement (Tagami and Watanabe 2007).

Similar results were obtained when MNSV cell-to-cell movement was recorded in the presence of the Sarlp mutant (Sar1[H74L]) or with the pMOG800 binary vector used as a control (described below). After quantifying more than 1,000 infection foci for each case, it was observed that the inhibition of the ER-Golgi secretion system, caused by the overexpression of the Sar1[H74L] mutant, had a drastic effect on viral infection (Fig. 7; Supplementary Fig. 2). Thus, on two consecutive days of Sar1[H74L] treatment (3 and 4 days postinfiltration [dpi]), almost all of the infection foci (97.2 and $97.8 \%$, respectively) showed a size ranging from 0 to $0.5 \mathrm{~mm}^{2}$ (Fig. $7 \mathrm{~A}$, gray bars). Under the control conditions, however, a large number of small infected areas (less than $0.5 \mathrm{~mm}^{2}$ ) were still observed at 3 dpi (65.6\%) (Fig. 7A, white bars), whereas the percentage of infection areas ranging from 1 to $5 \mathrm{~mm}^{2}$ significantly increased at $4 \mathrm{dpi}$. To further demonstrate that this effect is MNSV specific, we used TMV as an additional control because the intracellular traffic to the PD of its MP is mediated by the actin-ER network during infection (Wright et al. 2007). Then, the same experiment was carried out by inoculating the in vitro transcripts from the TMV DsREd plasmid (Gillespie et al. 2002). In this case, the infection foci size distribution was very similar in both the control and Sar1[H74L]expressing $N$. benthamiana leaves at either 3 or 4 dpi (Fig. 7B). Collectively, these results clearly demonstrate that the ER-to-Golgi secretory pathway has a specific influence on MNSV movement, most probably due to the relationship between this route and the p7B subcellular distribution pattern.

\section{DISCUSSION}

Most plant viruses encode for specialized MP that facilitate their intra- and intercellular trafficking (Waigmann et al. 2004; Lucas 2006). These proteins are able to interact with the plant macromolecular transport systems to carry out their functions. The trafficking of cargo proteins in plant cells requires an
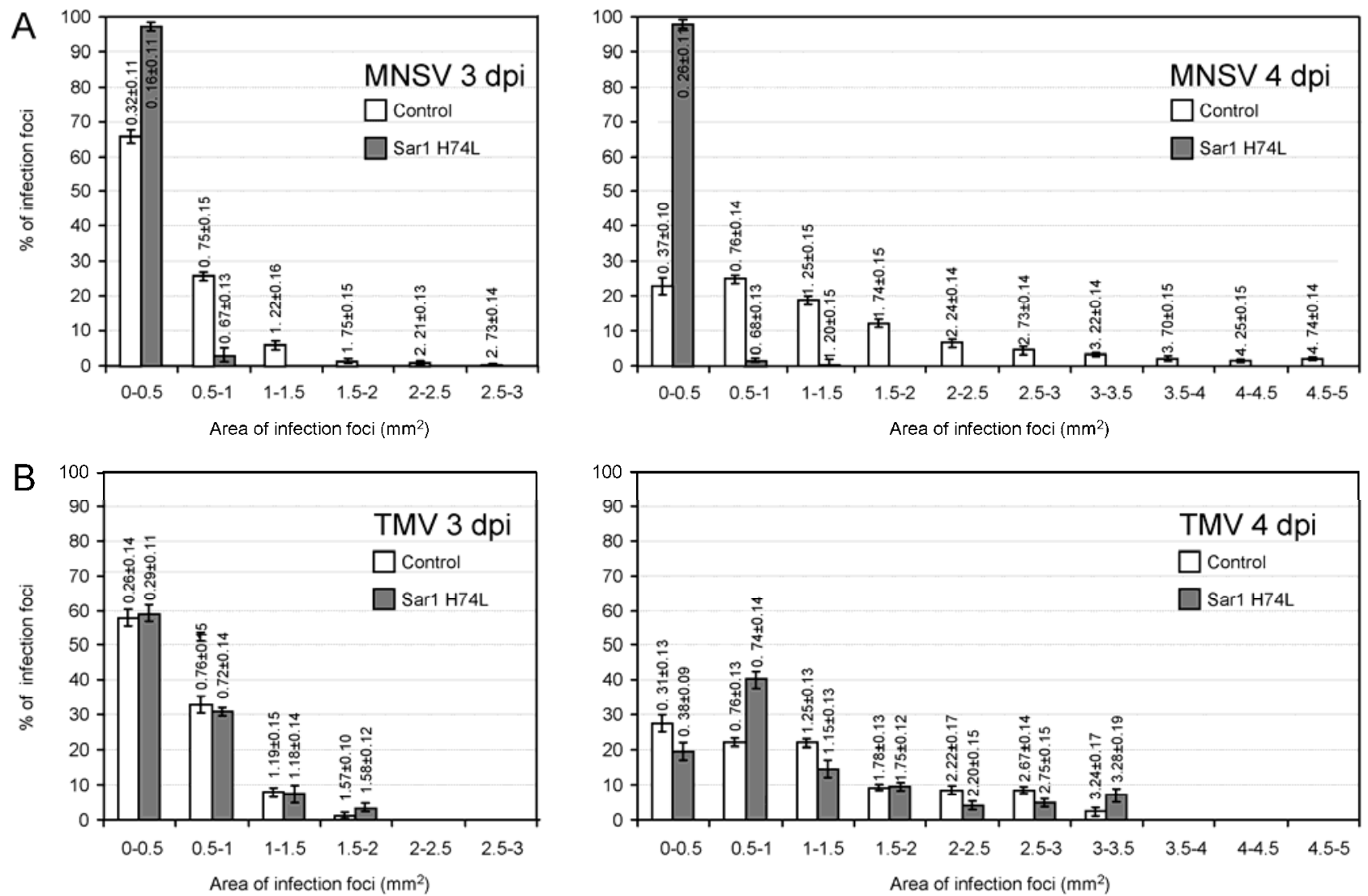

Fig. 7. Effect of Sar1[H74L] on A, Melon necrotic spot virus (MNSV) and B, Tobacco mosaic virus (TMV) cell-to-cell movement. Bar diagram representing the percentage of the infection foci observed on the Nicotiana benthamiana leaves inoculated either with MNSV(Al/264)Dcp-green fluorescent protein (GFP) or TMV-red fluorescent protein (RFP) RNAs, and grouped according to size. Inoculation was performed after either agroinfiltration of pMOG800 (white bars) or pMOG-Sar1[H74L] (gray bars) containing bacteria. The area of the infection foci (in $\mathrm{mm}^{2}$ ) is displayed under the corresponding bars. The data correspond to 3 and 4 days postinfiltration (dpi), as indicated on the upper side of each representation. The mean value of the infection foci area and the corresponding standard deviation from each group is indicated either inside or above each bar. 
intricate endomembrane system defining highly dynamic subcellular compartments (i.e., ER, GA, endosomes, prevacuoles, and a great variety of vacuoles) that are functionally assisted by a network of actomyosin microfilaments and microtubules (Jürgens 2004). In this scenario, the ER represents the major entry port for newly synthesized proteins while the GA plays a central role in the correct distribution of a variety of cargo molecules to the appropriate pathway toward cell wall, plasma membrane, external surface, storage, and lytic vacuoles (Matheson et al. 2006; Moreau et al. 2007). Additionally, GA has been described as an alternative route to the chloroplasts, mitochondria, peroxisomes (Matheson et al. 2006), and, recently, PD (Sagi et al. 2005; Thomas et al. 2008). In this study, we examined the implication of the ER-to-Golgi vesicle transport pathway not only on the intracellular location of the MNSV p7B MP but also on virus infection. The approach used for the subcellular localization studies consisted of the transient expression of the p7B fused to either GFP or RFP. In this sense, previously reported data have shown identical results on MP localization during transient assays and viral infection of recombinant TMV MP and TGBps. Therefore, transient expression experiments could provide evidences about the intracellular pathway that the protein follows to reach its target during viral infection (Samuels et al. 2007; Waigmann et al. 2007).

Biochemical studies on $\mathrm{p} 7 \mathrm{~B}$ have revealed the presence of a single-spanning membrane domain that allowed its co-translational insertion into ER-derived microsomal membranes (Navarro et al. 2006; Martínez-Gil et al. 2007). By using different subcellular markers, we have demonstrated that GFPp7B was mainly localized in the ER, at the Golgi stacks, and in the actin-cytoskeleton at 24 to $36 \mathrm{hpi}$, and also at PD at later times (Figs. 2 and 4). The co-localization with Golgi stacks was additionally proved by the biochemical fractionation of membrane preparations and by comparing the average velocities of the GFP-p7B bodies versus the Golgi stacks (Fig. 3; Results section). These results indicate the ER-to-Golgi trafficking of the viral MP p7B. We also determined that the secretory pathway inhibitor BFA or the overexpression of the defective mutant Sar1[H74L] fully retain the p7B-derived fluorescence in the ER (Fig. 4). In addition, p7B localization was strongly modified in the presence of the actin skeleton inhibitor Lat B, suggesting that the p7B pathway to the PD is F-actin dependent (Fig. 5).

The involvement of the secretory pathway in the targeting to PD for a nonviral protein has been previously reported for the PD-associated cellular class 1 reversibly glycosylated polypeptide RGP2 from A. thaliana (Sagi et al. 2005). In addition, the characterization of a plasmodesmal-located protein (PDLP1a), which is targeted to the PD via the secretory pathway in a BFA-sensitive and COP II-dependent manner, has been recently reported (Thomas et al. 2008). Interestingly, this plant protein is highly similar to $\mathrm{p} 7 \mathrm{~B}$ because it has a TMD of the same length and with almost an identical hydropathy value (Supplementary Fig. 3). The involvement of the secretory pathway or cytoskeleton in viral intracellular targeting was first demonstrated for the viral MP of GFLV (Laporte et al. 2003). More recently, Vogel et al. (2007) analyzed Arabidopsis plants expressing the PLRV 17-KDa MP (MP17) fused to GFP to show that this MP is targeted to PD in an actin- and ER-Golgidependent manner. In contrast to our results, none of these MP have been directly observed in association with the GA. Moreover, the effects of the ER-to-Golgi route inhibition on virus infection were not addressed in these two works. Whereas here, we observe that either BFA or the mutant Sar1[H74L] had a significant inhibitory effect on virus infection. The number of GFP foci harboring more than six cells was almost half that observed in the control leaves. Because viral accumulation was similar in both cases, this effect was very probably due to inhibition on the virus cell-to-cell movement.

According to the mechanism described here, the early secretory pathway also may be used by some viral factors, different from MP, to move from ER to GA. For example, the two glycoproteins of the TSWV, Gn and Gc, are transported to Golgi in a COPII-dependent manner, playing a key role in membrane envelope acquisition by TSWV particles but not in viral movement (Ribeiro et al. 2008, 2009). In other cases, ER exit could be dependent on early secretory pathway components although the viral factor could not finally be targeted to the GA. For example, the 6-kDa Potyvirus protein (6K), involved in the generation of a membranous replication complex, was shown to induce the formation of vesicles from ER exit sites in a dependent manner on the early secretory pathway (Wei and Wang 2008). In this sense, it has been suggested that the Golgi also may be bypassed in a few cases by plant factors. For example, some proprotein precursors are transported directly to storage vacuoles by means of ER-derived vesicles in maturing pumpkin seed (Hara-Nishimura et al. 1998; Toyooka et al. 2000) and the barley aspartic protease could be secreted in either a COPII-dependent or independent manner depending on the presence or absence, respectively, of a vacuolar targeting domain (Törmäkanagas et al. 2001).

In short, our data provide evidence suggesting that an active COPII-dependent early secretory pathway is required for the intra- and intercellular cell-to-cell movement of MNSV, demonstrating the involvement of the GA in this process. It would be interesting to know whether these observations constitute a general rule for the rest of the Carmovirus spp.

\section{MATERIALS AND METHODS}

\section{Construction of binary vectors for fluorescent-tagged p7B recombinant proteins expression and fluorescent-tagged markers of subcellular compartments.}

The p7B ORF was amplified from the pMNSV(Al) vector containing the full-length sequence of the MNSV-Al genome (accession number DQ339157) (Gosalvez-Bernal et al. 2003; Genoves et al. 2006). The corresponding cDNA was fused in frame to the $3^{\prime}$ end of the GFP gene, GFP-p7B, by standard molecular cloning procedures (Sambrook et al. 2007 or to the mRFP, mRFP-p7B. These constructs were inserted between the $35 \mathrm{~S}$ promoter of Cauliflower mosaic virus and the Solanum tuberosum proteinase inhibitor terminator (PoPit) in the pMOG800 binary vector (Knoester et al. 1998).

The fluorescent organelle markers used in co-localization assays with fluorescent-tagged p7B included the TMV MP fused to mRFP ORF (MPTMV mRFP) and the A. thaliana reversibly glycosylated polypeptide fused to (AtRGP2-GFP), both of which were used for PD labeling (Heinlein et al. 1998; Sagi et al. 2005); a cytoskeleton-targeted recombinant protein consisting of the actin-biding domain of the mouse talin fused to the dsRFP (dsRFP-Talin) (Kost et al. 1998); the rat $\alpha$-2,6-sialyltransferase fused to either the YFP or the cherry fluorescent protein (ChFP) (STtmd-YFP and STtmd-Cherry, respectively), both employed as trans-Golgi-specific fluorescent reporters (Boevink et al.1998); a mannosidase Golgi's resident fused to GFP (Gman-GFP) as cis-Golgi-specific marker (Nebenfuhr et al. 1999); a ChFP-tagged peroxisome marker (Sparkes et al. 2005); the fusion of the N. plumbaginifolia $\beta$-ATPase with GFP, a mitochondrion-specific reporter (Logan and Leaver 2000); and, finally, an ER marker engineered by cloning the ERtargeting sequence of calreticulin sequence encoding the ER retrieval sequence KDEL at the $3^{\prime}$ end of GFP (GFP-KDEL) (Boevink et al. 1996). Transient expression assays on $N$. benthamiana plants were performed as previously described (Genoves et al. 2006). 
Confocal laser-scanning microscopy and Golgi velocity quantifying.

Plant tissue was observed with both Zeiss LSM 510 META (Zeiss) and Leica TCS SL (Leica) spectral confocal microscopes using either an HC PL FLUOTAR $\times 10 / 0.3$ or an HCX PL APO $\times 40 / 1.25-0.75$ oil CS objective. For Leica TCS SL, GFP- or YFP-derived fluorescence was monitored by excitation with 488- and 514-nm argon laser lines, respectively, and emission was visualized with a 30-nm-width band-pass window centered at $515 \mathrm{~nm}$. When mRFP and ChFP were used, excitation was performed by means of a 543-nm green-neon laser line, and fluorescence emission was collected at 610 to $630 \mathrm{~nm}$.

The velocity at which GFP-p7B and STtmd-YFP fluorescent particles moved was manually estimated with the Zeiss LSM image browser software. Briefly, 10 movie files consisting of a stack of 25 consecutive frames were recorded from different epidermic cells, and the distance covered by more than 40 individual fluorescent bodies of each type from the initial slices to the next successive slices was measured. The time interval between frames was known; therefore, the velocity of each tracked particle was obtained and an average velocity was calculated.

\section{Sucrose gradient of microsomal fractionation and immunoblotting.}

Approximately $2 \mathrm{~g}$ of $N$. benthamiana leaves individually expressing GFP-p7B, STtmd-YFP, and GFP-KDEL by agroinfection were homogenized in lysis buffer containing $20 \mathrm{mM}$ HEPES, pH $6.8 ; 150 \mathrm{mM}$ potassium acetate; $250 \mathrm{mM}$ mannitol; and $1 \mathrm{mM} \mathrm{MgCl}_{2}$. Large cellular debris were removed by gentle centrifugation at $3,000 \times g$ for $10 \mathrm{~min}$, and the resulting supernatant was ultracentrifuged at $30,000 \times g$ for $1 \mathrm{~h}$ to generate the soluble (S30) and the microsomal (P30) fractions. Then, the P30 fraction was resuspended in $2 \mathrm{ml}$ of lysis buffer containing $5 \mathrm{mM} \mathrm{MgCl}$ and, later, it was loaded on top of 20 to $60 \%$ linear sucrose gradients containing lysis buffer with the same $\mathrm{MgCl}_{2}$ concentration. The gradient was centrifuged for $16 \mathrm{~h}$ at $100,000 \times g$ in a Beckman SW40 rotor at $4^{\circ} \mathrm{C}$, and 18 fractions were taken starting from the bottom. Samples from each fraction were analyzed by sodium dodecyl sulfate polyacrylamide gel electrophoresis in $12 \%$ polyacrylamide gels, and were subsequently transferred to polyvinylidene fluoride membranes (Amersham Biosciences Piscataway, NJ, U.S.A.) for immunoblotting with a mouse polyclonal antibody to GFP, which also recognizes YFP (Roche Diagnostics, Mannheim, Germany) (Gomez and Pallas 2007).

\section{BFA and LatB treatments.}

A stock of BFA (Invitrogen, Carlsbad, CA, U.S.A.) was dissolved in DMSO solvent at $10 \mathrm{mg} / \mathrm{ml}$. For subcellular localization experiments, leaf discs from $N$. benthamiana plants transiently expressing either STtmd-YFP or GFP-p7B were immersed into the BFA solution $(10 \mu \mathrm{g} / \mathrm{ml})$ for $5 \mathrm{~h}$ at $24 \mathrm{hpi}$ of the Agrobacterium tumefaciens cultures. Controls were performed by leaf disc immersion into DMSO. For experiments on GFP-p7B movement evaluation in the presence of LatB (Sigma, St. Louis), the protein was transiently expressed in $N$. benthamiana leaves and then infiltrated with a DMSO stock solution containing the drug. Optimal drug concentration (25 $\mu \mathrm{M}$ in DMSO) and treatment length (up to $24 \mathrm{~h}$ ) resulting in desired effects was determined in preliminary experiments on $N$. benthamiana leaves that express the RFP-Talin microfilament marker. In all cases, the tissue was visualized by using a Leica TCS SL spectral confocal microscope.

The effect of BFA on MNSV cell-to-cell movement was evaluated by using $N$. benthamiana leaves. This plant is a host for isolate MNSV-264, which possesses an avirulence determinant in its $3^{\prime}$ untranslated region (UTR), allowing the infection of non cucurbit species (Diaz et al. 2004). Thus, the pMNSV(Al) $\Delta$ cp-GFP clone was modified by replacing its $3^{\prime}$ UTR from that of the isolate MNSV-264 (pMNSV(Al/264) $\Delta \mathrm{cp}-\mathrm{GFP})$, and was cloned into pMOG800. Briefly, six different $N$. benthamiana plants were infected with MNSV(Al/264) $\Delta \mathrm{cp}-\mathrm{GFP}$ by agroinfitration (two leaves/plant). At $3 \mathrm{dpi}$, inoculated leaves were cut and hydroponically maintained in Murashige and Skoog (MS) medium containing either BFA solution at $10 \mu \mathrm{g} / \mathrm{ml}$ or $0.1 \%$ DMSO as a control (six leaves/ treatment). After $12 \mathrm{~h}$, the BFA-treated leaves were transferred to the MS medium with $0.1 \%$ DMSO for $12 \mathrm{~h}$ to avoid cellular death. Then, the 12-h BFA treatment was repeated once more. The size of infection foci was measured at 5 dpi by quantifying the number of fluorescent cells by confocal microscope imaging.

\section{Sar 1[H74L] assays.}

Sar1 ORF cDNA was polymerase chain reaction generated from $N$. tabacum messenger RNAs, cloned, and sequenced. The amino acid sequence was identical to that previously deposited in GenBank (AF210431). After this, the Sar1[H74L] mutation (Takeuchi et al. 2000) was introduced by using the QuickChangeR XL-site direct mutagenesis kit; then, modified ORF was cloned into pMOG800 binary vector (pMOG800Sar1[H74L]) (Knoester et al. 1998). For subcellular localization assays, $N$. benthamiana plants were coinfiltrated with Sar1[H74L] and either STtmd-YFP or GFP-p7B. For cell-tocell movement assays, $N$. benthamiana plants were infiltrated with $A$. tumefaciens containing pMOG800 or pMOG-Sar1 [H74L] and, 5 to $6 \mathrm{~h}$ later, infected with $\mathrm{MNSV}(\mathrm{Al} / 264) \Delta \mathrm{cp}-$ GFP or TMV.DsRed RNAs (three leaves/plant). Images from inoculated leaves were collected at 3 to $4 \mathrm{dpi}$ by Leica Z16 APO Stereomicroscope and were processed by ImageJ-1.41 Software. Data were represented by using Statgraphics Plus 5.0 Software.

\section{Total RNA extraction and Northern-blot assays.}

Total nucleic acids extraction from $N$. benthamiana leaves was performed as previously described (Navarro et al. 2006). RNAs were electrophoresed through formaldehyde-denatured gel and transferred to positively charged nylon membranes (Roche Mannheim, Germany). Northern-blot membranes were air dried and nucleic acids were bound using a UV cross-linker (700 by $100 \mu \mathrm{J} \mathrm{cm}^{-2}$ ). Viral RNAs detection was carried out as previously described (Pallas et al. 1998) using a dig-riboprobe (Roche Mannheim) complementary to a region of MNSV-Al p42 ORF (Gosalvez-Bernal et al. 2003).

\section{ACKNOWLEDGMENTS}

This work was supported by grant BIO08-03528 from the Spanish granting agency DGICYT. J. A. Navarro and A. Genovés are recipients of an I3P contract and a Ph.D. fellowship from the Consejo Superior de Investigaciones Científicas and the Spanish Ministerio de Educacion y Ciencia, respectively. We thank M. C. Herranz for the critical reading of the manuscript, L. Corachán and L. Latorre for their technical assistance, V. V. Dolja (Oregon State University, U.S.A.) for providing all the organelle markers used in this study, and S. Chapman (SCRI, Dundee, Scotland, U.K.) and F. Garcia-Arenal (CBGP, Madrid) for their generous gift of the TMV infectious clone.

\section{LITERATURE CITED}

Ashby, J., Boutant, E., Seemanpillai, M., Groner, A., Sambade, A., Ritzenthaler, C., and Heinlein, M. 2006. Tobacco mosaic virus movement protein functions as a structural microtubule-associated protein. J. Virol. 80:12433-12433. 
Avisar, D., Prokhnevsky, A. I., Makarova, K. S., Koonin, E. V., and Dolja, V. V. 2008. Myosin XI-K Is required for rapid trafficking of Golgi stacks, peroxisomes, and mitochondria in leaf cells of Nicotiana benthamiana. Plant Physiol. 146:1098-108.

Boevink, P., and Oparka, K. J. 2005 Virus-host interactions during movement processes. Plant Physiol.138:1815-1821.

Boevink, P., Santa Cruz, S., Hawes, C., Harris, N., and Oparka, K. J. 1996. Virus-mediated delivery of the green fluorescent protein to the endoplasmic reticulum of plant cells. Plant J. 10:935-941.

Boevink, P., Oparka, K., Santa Cruz, S., Martin, B., Betteridge, A., and Hawes, C. 1998. Stacks on tracks: The plant Golgi apparatus traffics on an actin/ER network. Plant J. 15:441-447.

Brandner, K., Sambade, A., Boutant, E., Didier, P., Mély, Y., Ritzenthaler C., and Heinlein, M. 2008. Tobacco mosaic virus movement protein interacts with green fluorescent protein-tagged microtubule end-binding protein. Plant Physiol. 147:611-623.

Christensen, N., Tilsner, J., Bell, K., Hammann, P., Parton, R., Lacomme, C., and Oparka, K. 2009. The 5' cap of Tobacco mosaic virus (TMV) is required for virion attachment to the actin/ER network during early infection. Traffic 10:536-551.

Diaz, J. A., Nieto, C., Moriones, E., Truniger, V., and Aranda, M. A. 2004. Molecular characterization of a Melon necrotic spot virus strain that overcomes the resistance in melon and non-host plants. Mol. PlantMicrobe Interact. 17:668-675.

Genoves, A., Navarro, J. A., and Pallas, V. 2006. Functional analysis of the five Melon necrotic spot virus genome-encoded proteins. J. Gen. Virol. 87:2371-2380.

Gillespie, T., Boevink, P., Haupt, S., Roberts, A. G., Toth, R., Valentine, T., Chapman, S., and Oparka, K. J. 2002. Analysis of a DNA-shuffled movement protein reveals that microtubules are dispensable for the cellto-cell movement of Tobacco mosaic virus. Plant Cell 14:1207-1222.

Gómez, G., and Pallás, V. 2007. Mature monomeric forms of Hop stunt viroid resist RNA silencing in transgenic plants. Plant J. 51:1041-1049.

Gosalvez-Bernal, B., Navarro, J. A., Lorca, A., Botella, F., Sanchez-Pina, M. A., and Pallas, V. 2003. Detection of Melon necrotic spot virus in water samples and melon plants by molecular methods. J. Virol. Methods 113:87-93.

Gosalvez-Bernal, B., Genoves, A., Navarro, J. A., Pallás, V., and SanchezPina, M. A. 2008. Distribution and pathway for phloem-dependent movement of Melon necrotic spot virus in melon plants. Mol. Plant Pathol. 9:447-461.

Guenoune-Gelbart, D., Elbaum, M., Sagi, G., Levy, A., and Epel, B. L. 2008. Tobacco mosaic virus (TMV) replicase and movement protein function synergistically in facilitating TMV spread by lateral diffusion in the plasmodesmal desmotubule of Nicotiana benthamiana. Mol. Plant-Microbe Interact. 21:335-345.

Hara-Nishimura, I., Shiada, T., Hatano, K., Takeuchi, Y., and Nishimura, M 1998. Transport of storage proteins to protein storage vacuoles is mediated by large precursor-accumulating vesicles. Plant Cell 10:825-836.

Harries, P. A., Park, J. W., Sasaki, N., Ballard, K. D., Maule, A. J., and Nelson, R. S. 2009 Differing requirements for actin and myosin by plant viruses for sustained intercellular movement. Proc. Natl. Acad. Sci. U.S.A. 106:17594-17599.

Haupt, S., Cowan, G. H., Ziegler, A., Roberts, A. G., Oparka, K. J., and Torrance, L. 2005. Two plant-viral movement proteins traffic in the endocytic recycling pathway. Plant Cell 17:164-181.

Heinlein, M., Padgett., H. S., Gens., J. S., Pickard., B. G., Casper., S. J., Epel., B. L., and Beachy, R. N. 1998. Changing patterns of localization of the tobacco mosaic virus movement protein and replicase to the endoplasmic reticulum and microtubules during infection. Plant Cell 10:1107-1120.

Hirashima, K., and Watanabe, Y. 2003. RNA helicase domain of Tobamovirus replicase executes cell-to-cell movement possibly through collaboration with its nonconserved region. J. Virol. 77:12357-12362.

Hofmann, C., Niehl, A., Sambade, A., Steinmetz, A., and Heinlein, M. 2009. Inhibition of Tobacco mosaic virus movement by expression of an actin-binding protein. Plant Physiol. 149:1810-1823.

Holweg, C. L. 2007. Living markers for actin block myosin-dependent motility of plant organelles and auxin. Cell Motil. Cytoskelet. 64:69-81.

Jackson, A. O., Lim, H. S., Bragg, J., Ganesan, U., and Lee, M. Y. 2009. Hordeivirus replication, movement, and pathogenesis Annu. Rev. Phytopathol. 47:385-422.

Ju, H. J., Samuels, T. D., Wang, Y. S., Blancaflor, E., Payton, M., Mitra, R., Krishnamurthy, K., Nelson, R. S., and Verchot-Lubicz, J., 2005. The Potato virus $X$ TGBp2 movement protein associates with endoplasmic reticulum-derived vesicles during virus infection. Plant Physiol. 138:1877-1895.

Ju, H.-J., Brown, J. E., Ye, C.-M., and Verchot-Lubicz, J. 2007. Mutations in the central domain of Potato virus $X$ TGBp2 eliminate granular vesicles and virus cell-to-cell trafficking. J. Virol. 81:1899-1911.
Jürgens, G. 2004. Membrane trafficking in plants. Annu. Rev. Cell Dev. Biol. 20:481-504.

Kawakami, S., Watanabe, Y., and Beachy, R. N. 2004. Tobacco mosaic virus infection spreads cell to cell as intact replication complexes. Proc. Natl. Acad. Sci. U.S.A. 101:6291-6296.

Knoester, M., van Loon, L. C., van den Heuvel, J., Hennig, J., Bol, J. F., and Linthorst, H. J. M. 1998. Ethylene-insensitive tobacco lacks nonhost resistance against soil-borne fungi. Proc. Natl. Acad. Sci. U.S.A. 95:1933-1937.

Kost, B., Spielhofer, R., and Chua, N.-H. 1998. A GFP-mouse talin fusion protein labels plant actin filaments in vivo and visualizes the actin cytoskeleton in growing pollen tubes. Plant J. 16:393-401.

Laporte, C., Vetter, G., Loudes, A., Robinson, D. G., Hillmer, S., StussiGaraud, C., and Ritzenthaler, C. 2003. Involvement of the secretory pathway and the cytoskeleton in intracellular targeting and tubule assembly of Grapevine fanleaf virus movement protein in tobacco BY-2 Cells. Plant Cell 15:2058-2075.

Lichtscheidl, I. K., and Baluška, F. 2000. Motility of endoplasmic reticulum in plant cells. Pages 191-202 in: Actin: A Dynamic Framework for Multiple Plant Cell Functions. Kluwer Academic Publishers, Dordrecht, The Netherlands.

Lim, H. S., Bragg, J. N., Ganesan, U., Ruzin, S., Schichnes, D., Lee, M. Y., Vaira, A. M., Ryu, K. H., Hammond, J., and Jackson, A. O. 2009. Subcellular localization of the Barley stripe mosaic virus triple gene block proteins. J. Virol. 83:9432-9448.

Liu, J. Z., Blancaflor, E. B., and Nelson, R. S. 2005. The Tobacco mosaic virus 126-kilodalton protein, a constituent of the virus replication complex, alone or within the complex aligns with and traffics along microfilaments. Plant Physiol. 138:1853-1865.

Liu, D. Y. T., Kuhlmey, B. T., Smith, P. M. C., Day, D. A., Faulkner, C. R. and Overall, R. L. 2008. Reflection across plant cell boundaries in confocal laser scanning microscopy. J. Microsc. 231:349-357.

Logan, D. C., and Leaver, C. J. 2000. Mitochondria-targeted GFP highlights the heterogeneity of mitochondrial shape, size and movement within living plant cells. J. Exp. Bot. 51:865-871.

Lucas, W. J. 2006. Plant viral movement proteins: Agents for cell-to-cell trafficking of viral genomes. Virology 344:169-184.

Martínez-Gil, L., Saurí, A., Vilar, M., Pallas, V., and Mingarro, I. 2007. Membrane insertion of the p7B movement protein of Melon necrotic spot virus (MNSV). Virology 367:348-357.

Matheson, L. A., Hanton, S. L., and Brandizzi, F. 2006.Traffic between the plant endoplasmic reticulum and Golgi apparatus: To the Golgi and beyond. Curr. Opin. Plant Biol. 9:601-609.

Melcher, U. 2000. The ' $30 \mathrm{~K}$ ' superfamily of viral movement proteins. J. Gen. Virol. 81:257-266.

Moreau, P., Brandizzi, F., Hanton, S., Chatre, L., Melser, S., Hawes, C., and Satiat-Jeunemaitre, B. 2007. The plant ER-Golgi interface: A highly structured and dynamic membrane complex. J. Exp. Bot. 58:49-64.

Morozov, S. Y., and Solovyev, A. G. 2003. Triple gene block: Modular design of a multifunctional machine for plant virus movement. J. Gen. Virol. 84:1351-1366.

Navarro, J. A., Genoves, A., Climent, J., Sauri, A., Martinez-Gil, L., Mingarro, I., and Pallas, V. 2006. RNA-binding properties and membrane insertion of Melon necrotic spot virus (MNSV) double gene block movement proteins. Virology 356:57-67.

Nebenfuhr, A., Gallagher, L. A., Dunahay, T. G., Frohlick, J. A., Mazurkiewicz, A. M., Meehl, J. B., and Staehelin, L. A. 1999. Stopand-go movements of plant Golgi stacks are mediated by the actomyosin system. Plant Physiol. 121:1127-1142.

Nelson, R. S., and Citovsky, V. 2005. Plant viruses. Invaders of cells and pirates of cellular pathways. Plant Physiol. 138:1809-1814.

Pallás, V., Más, P., and Sánchez-Navarro, J. A. 1998. Detection of plan RNA viruses by nonisotopic dot-blot hybridization. Methods Mol. Biol. 81:461-468.

Pouwels, C., Carette, J. E., van Lent, J., and Wellink, J. 2002. Cowpea mosaic virus: Effects on host cell processes. Mol. Plant. Pathol. 3:411-418.

Ribeiro, D., Foresti, O., Denecke, J., Wellink, J., Goldbach, R., and Kormelink, R. J. 2008. Tomato spotted wilt virus glycoproteins induce the formation of endoplasmic reticulum- and Golgi-derived pleomorphic membrane structures in plant cells. J. Gen. Virol. 89:1811-1818.

Ribeiro, D., Goldbach, R., and Kormelink, R. 2009. Requirements for ERarrest and sequential exit to the Golgi of Tomato spotted wilt virus glycoproteins. Traffic 10:664-672.

Ritzenthaler, C., Nebenfuhr, A., Movafeghi, A., Stussi-Garaud, C., Behnia, L., Pimpl, P., Staehelin, L. A., and Robinson, D. G. 2002. Reevaluation of the effects of Brefeldin A on plant cells using tobacco bright yellow 2 cells expressing Golgi-targeted green fluorescent protein and COPI antisera. Plant Cell 14:237-261.

Riviere, C. J., and Rochon, D. M. 1990. Nucleotide sequence and genomic organization of Melon necrotic spot virus. J. Gen. Virol. 71:1887-1896. 
Sagi, G., Katz, A., Guenoune-Gelbart, D., and Epel, B. L. 2005. Class 1 reversibly glycosylated polypeptides are plasmodesmal-associated proteins delivered to plasmodesmata via the Golgi apparatus. Plant Cell 17:1788-800.

Sambade, A., Brandner, K., Hofmann, C., Seemanpillai, M., Mutterer, J., and Heinlein, M. 2008. Transport of TMV movement protein particles associated with the targeting of RNA to plasmodesmata. Traffic 9:20732088

Sambrook, J., Fritsch, E. F., and Maniatis, T. 2007. Molecular Cloning: A Laboratory Manual. Cold Spring Harbor Laboratory Press, Cold Spring Harbor, NY, U.S.A.

Samuels, T. D., Ju, H. J., Ye, C. M., Motes, C. M., Blancaflor, E. B., and Verchot-Lubicz, J. 2007. Subcellular targeting and interactions among the Potato virus X TGB proteins. Virology 367:375-389.

Sanchez-Navarro, J. A., Miglino, R., Ragozzino, A., and Bol, J. F. 2001. Engineering of Alfalfa mosaic virus RNA 3 into an expression vector. Arch. Virol. 146:923-939.

Sánchez-Navarro, J. A., Herranz, M. C., and Pallás, V. 2006. Cell-to-cell movement of Alfalfa mosaic virus can be mediated by the movement proteins of Ilar-, bromo-, cucumo-, tobamo- and comoviruses and does not require virion formation. Virology 346:66-73.

Schepetilnikov, M. V., Solovyev, A. G., Gorshkova, E. N., Schiemann, J., Prokhnevsky, A. I., Dolja, V. V., and Morozov, S. Y. 2008. Intracellular targeting of a hordeiviral membrane-spanning movement protein: Sequence requirements and involvement of an unconventional mechanism. J. Virol. 82:1284-1293.

Sparkes, I. A., Hawes, C., and Baker, A. 2005. AtPEX2 and AtPEX10 are targeted to peroxisomes independently of known endoplasmic reticulum trafficking routes. Plant Physiol. 139:690-700.

Tagami, Y., and Watanabe, Y. 2007. Effects of brefeldin A on the localization of Tobamovirus movement protein and cell-to-cell movement of the virus. Virology 361:133-140.

Takeuchi, M., Ueda, T., Sato, K., Abe, H., Nagata, T., and Nakano, A. 2000. A dominant negative mutant of Sar1 GTPase inhibits protein transport from the endoplasmic reticulum to the Golgi apparatus in tobacco and Arabidopsis cultured cells. Plant J. 23:517-525.
Thomas, C., Bayer, E. M., Ritzenthaler, C., Fernandez-Calvino, L., and Maule, A. J. 2008. Specific targeting of a plasmodesmal protein affecting cell-to-cell communication. PLOS Biol. 6:1-11.

Törmäkanagas, K., Hadlington, J. L., Pimpl, P., Hillmer, S., Brandizzi, F., Teeri, T. H., and Denecke, J. 2001. A vacuolar sorting domain may also influence the way in which proteins leave the endoplasmic reticulum. Plant Cell 13:2021-2032.

Toyooka, K., Okamoto, T., and Minamikawa, T. 2000. Mass transport of a preform of a KDEL-tailed cystein proteinase (SH-EP) to protein storage vacuoles by endoplasmic reticulum-derived vesicle is involved in protein mobilization in germinating seeds. J. Cell. Biol. 148:453-463.

Verchot-Lubicz, J., Ye, C. M., and Bamunusinghe, D. 2007. Molecular biology of potexviruses: Recent advances. J. Gen. Virol. 88:1643-1655.

Vogel, F., Hofius, D., and Sonnewald, U. 2007. Intracellular trafficking of Potato leafroll virus movement protein in transgenic Arabidopsis. Traffic 8(9):1205-1214.

Waigmann, E., Ueki, S., Trutnyeva, K., and Citovsky, V. 2004. The ins and outs of non-destructive cell-to-cell and systemic movement of plant viruses. Crit. Rev. Plant Sci. 23:195-250.

Waigmann, E., Curin, M., and Heinlein, M. 2007. Tobacco mosaic virusa model for macromolecular cell-to-cell spread. Pages 29-62 in: Viral Transport in Plants. E. Waigmann and M. Heinlein, eds. Springer-Verlag, Berlin, Heidelberg.

Wei, T., and Wang, A. 2008. Biogenesis of cytoplasmic membranous vesicles for plant potyvirus replication occurs at endoplasmic reticulum exit sites in a COPI- and COPII-dependent manner. J. Virol. 82:12252 12264.

Wright, K. M., Wood, N. T., Roberts, A. G., Chapman, S., Boevink, P., Mackenzie, K. M., and Oparka, K. J. 2007. Targeting of TMV movement protein to plasmodesmata requires the actin/ER network: Evidence from FRAP. Traffic 8:21-31

Yang, Y., Elamawi, R., Bubeck, J., Pepperkok, R., Ritzenthaler, C., and Robinson, D. G. 2005. Dynamics of COPII vesicles and the Golgi apparatus in cultured Nicotiana tabacum BY-2 cells provides evidence for transient association of Golgi stacks with endoplasmic reticulum exit sites. Plant Cell 17:1513-1531. 